perature, residence in the hopper) is of crucial importance, but given the right conditions of flow function can be derived which is an invaluable aid to hopper design, and which is capable of forecasting differences in flow behaviour of otherwise seemingly identical powders. The questions dealt with the design of bunkers, the degree of standardization of Jenike's procedure and its applicability to damp and wet materials, the treatment of powders of very low bulk density (magnesium carbonate at $8-9 \mathrm{lb} . / \mathrm{ft}^{3}{ }^{3}$, mechanical aids to hopper discharge and the effects of flow-promoters.

The meeting was closed with a vote of thanks to speakers, audience and organizers by Dr. Kitchener, who also announced that preparations for a third regional meeting on powder technology topics in the spring were under way.

\title{
TRANSPORT AND TRAFFIC NOISE
}

A SYMPOSIUM on "Transport and Traffic Noise" was held in the University of Southampton during September 27-28. The symposium, which was sponsored by the Society of Acoustic Technology and the Institute of Sound and Vibration Research of the University of Southampton, was attended by about 130 people representing various firms related to the motor industry, local government authorities, universities and colleges of advanced technology.

The symposium was opened with a lecture by Prof. E. J. Richards, the director of the Institute of Sound and Vibration, on the impact of the report of the Committee on the Problem of Noise, headed by Sir Alan Wilson. Prof. Richards, who was a member of the Committee, directed attention to the startling increase, which occurred between the 1948 and 1961 noise surveys, in the number of people who notice noise outside their homes42 per cent in 1948 and 91 per cent in 1961. The statistics given in the report suggest that road traffic noise is largely to blame for this incroaso. In fact, of the various external noises, 36 per cent of people questioned in 1961 found road traffic noise disturbing, compared with 9 per cent who were disturbed by aircraft noise. Prof. Richards discussed the findings of the Wilson Committee in general terms and described some of the recommendations which it had made.

The second lecture was given by Dr. B. W. Robinson (National Physical Laboratory) on the measurement of noise. Dr. Robinson outlined the various units which have been introduced for the measurement of noise and discussed the relation between the objective (db), the froquency weighted decibel (dbA), the unit of subjective assessment (phon), and the attempts which had been made by Stevens, Zwicker and others, to compute a single loudness figure which agrees closely with the phon. Dr. Robinson also discussed the standard practices which have been suggested for rating the noisiness of motor vehicles and which may soon be implemented by law.

The afternoon session was devoted to two technical lectures, by Dr. T. Priede (C.A.V., Ltd., Warple Way, London, W.3) and Dr. P. O. A. L. Davies (Institute of Sound and Vibration Research). Dr. Priede discussed the subject of engine noise, with particular reference to Diesel engine noise, illustrating his talk not only with slides, but also with tape recordings, which proved to be a much more efficient means of showing the result of decreasing a noise by a few decibels. Dr. Priede discussed the mechanics by which noise was created in a Diesel engine and described some of the extensive investigations which have bean carried out at C.A.V., Ltd.. to reduce it. Special mention was made of air-intake nnise, the reduction in noise which may be ohtrined by smoothing the cylinder pressure, and the noise produced by resonance of the engine casing.

In his lecture on silencer design. Dr. Davies compared the results which may be obtained from the traditional acoustic thaory of silencers, and the new shock wave theory which has been investigated by him and his co-workers at Southampton. Single-pulse shock wave theory can be used in discussing an exhaust system, becanse for a typical four-stroke engine running at 3,000 r.p.m. the primary pulses travel down the exhaust pipe at intervals of about $18 \mathrm{ft}$. Dr. Davies showed that the single pulse theory may be used to give a picture of the gas flow through the exhaust system, to calculate the back pressure, and to determine the attenuation which will be produced by the system. The acoustic filter theory still has its place in the field of harmonic response, but the single pulse theory describes the transient response in a way the older theory could never do.

The evening session of the conference consisted of an open lecture by Mr. H. Purkis, of the Building Research Station, on the subject of transport noise and town planning. Mr. Purkis first directed attention to the way in which noise nuisance has been growing and is likely to grow in the future, owing to the tremendous increase in vehicle ownership and industrialization. He then discussed some of the proposals which had been suggested for combating the nuisance in new towns. Motor-vehicles could not be prohibited from a town without killing all commorce, and it could not be expected that the noise-levels which were to be laid down for cars would be able to counteract the increase in overall noise-level which would be produced by the increasing number of vehicles.

Since overall noise-level must be expected to increase, means must be found to prevent the noise reaching houses, shops and offices. Mr. Purkis discussed sunken roads, smooth flowing motor-ways lined with specially insulated buildings to prevent the noise permeating to other dwellings, as well as some of the unsuccessful (that is, noise-producing) devices which were being used by traffic engineers to-day-one-way streots, which lead to faster, more noisy, traffic, and the use of side streets, which distributes the noise to parts of the town which were previously quiet.

On the Saturday morning, consideration was given to the problem of noise as it affects the passengers in a car. The first lecturer was Dr. G. M. L. Gladwell (Institute of Sound and Vibration Research), who presented a review of the literature on the subject. He paid particular attention to the noise caused by the passage of the tyres over the road, to the way in which this was transmitted through the car structure, and to the mechanical/acoustic properties of the passenger cabin. He also stressed the need for more fundamental investigation into the vibration characteristics of a car, and the use of electronic analogue computers to make the investigation of the vibration characteristics of a projected design more lngical and less a matter of guesswork. In the extended discussion period following this review, representatives from Peugeot, Ford. Humber, Pirelli and Dunlop contributed from their own experience. The discussion centred on the road noise problem. M. J. Genestier, director of the Peugeot Research Laboratory, explained how they had devised the suspension system of their 404 model sprcifically for the Michelin $X$ tyre, a tyre which excites vibration in a frequency range much narrower than others. and had managed so to tune the suspension system that the vibrations that were excited were not transmitted to the car. Other representatives stressed the need for car and tyre manufacturers to co-operate, and consider when designing a car the characteristics of the tyres which were to be fitted. 
Dr. A. Chiesa, from the Pirelli rubber laboratory in Milan, gave the next lecture on some experimental investigations which they had undertaken on the noise inside cars. After a genoral discussion on the various origins of the noise, Dr. Chiesa described the basic experimental method which is used. The noise produced in a running car varies in intensity and in frequency content. It must therefore be investigated by using statistical methods. Most of the important information about the noise could be obtained from its frequency spectrum, and Dr. Chiesa discussed the instruments which were used in the Pirelli laboratories to obtain this spectrum completely automatically. He then showed how the various kinds of vibration could be distinguished by an inspection of the spectrum, illustrating his remarks with slides of typical spectra obtained by driving over various kinds of road. Dr. Chiesa again emphasized the importanee of co-operation between car and tyre manufacturers, and described the kind of research programme they carry out when a certain manufacturer considers fitting one of their tyres.

The final lecture of the symposium was on the subject of hovercraft noise and was given by Prof. Richards. He began by pointing out that hovereraft present an extremely difficult noise problem, much greater than that of conventional aircraft or helicopters. They operate at ground-level, very often near to dwellings; their most likely means of propulsion is an airscrew, which is basically noisy, and at present they develop very high horse-power in a relatively flimsy structure. Prof. Richards went on to define the various noise sources-engines, propellers, fans, air jets, etc. All these sources can generate noise, which in turn can produce resonances in the aircraft structure. He then stressed that a fair estimate of the likely noise production of a hovercraft could not be obtained from prototypes, which inevitably were constructed from components already in use in aircraft, motor-cars, etc., and which were not designed specifically for hovercraft. Provided that proper attention was directed to the components, the design of the hovercraft could undoubtedly be modified to minimize the noise that was generated. Prof. Richards directed attention to the fact that the noise problem for conventional aircraft was realized only when they had been in use for many years, but that, provided sufficient pressure was exerted on designers, it could and should be dealt with at an early stage of the development of hovercraft.

Reports on the research work on which some of the lectures were based are to be publishéd in forthcoming issues of the new Journal of Sound and Vibration (Academic Press, Inc., London, Ltd.).

G. M. L. Gladwell

\section{FUNDAMENTAL ASPECTS OF COMBUSTION}

$\mathrm{T}$ HE annual Coal Science Lecture of the British Coal Utilization Research Association was established in 1951 in the belief-to use the words of Sir Charles Ellis, then its president--"that a Research Association should in its own particular field play a part analogous to that of the great learned societies and should, in addition to applying knowledge and attempting to produce immediate results, also take its share of responsibility in the progress of the fundamental work of its subject". The previous Lectures, which have proved eminently successful, were given by eight leading British scientists and three from overseas: Prof. D. W. van Krevelen (University of Delft), Monsieur R. Cheradame (Contre d'Etudes et Recherches des Charbonnages de France). and in 1962, Mr. H. Seidl (Deutsche Babcock and Wilcox Dampfkesselwerke).

The twelfth of the series was delivered by Dr. D. T. A. Townend at the Institution of Civil Engineers on October 16. Dr. Townend, who was until 1946 Livesey professor of coal gas and fuel industries in the University of Leeds, retired as director general of the British Coal Utilization Research Association in September 1962 and, when inviting him to give the lecture, the Association's Council suggested that he should speak on a subject to which his earlier work on the fundamental aspects of combustion was relevant: hence his title "Some Reflexions on Combustion".

Dr. Townend said that, on reflecting on a suitable theme, he had beon led more and more to appreciate how dominating an influence the combustion of the elementary combustibles, hydrogen and carbon monoxide, must play in the overall combustion and gasification of all solid fuels. For coal was first pyrolysed to yield combustible gases, volatile hydrocarbons and coke, the primary combustible gases being hydrogen and methane; and at temperatures above $700^{\circ} \mathrm{C}$, hydrogen was almost the sole product. Carbon monoxide was the primary product of the oxidation of coke and the volatile hydrocarbons yielded on pyrolysis ultimately hydrogen and carbon. Finally, even hydrocarbons were first transformed essentially into carbon monoxide and hydrogen before their overall combustion was completed. Some 30 per cent of the potential heat in coal was released during the production of carbon monoxide by the direct oxidation of carbonaceous material, and the remainder was released from the combustion of carbon monoxide and hydrogen. The presence of hydrogen and carbon monoxide in the combustion gases within a pulverized-fuel-fired furnace was illustrated from the present work of the International Flame Foundation at Ijmuiden.

Dr. Townend next directed attention to the important part played by hydrogen and oxygen atoms in the chain mechanisms inherent in the combustion of hydrogen and carbon monoxide; in flames their concentrations were greater than would be expected from theoretical considerations. The presence of hydrogen atoms was readily demonstrated by the phenomenon of candoluminescence whereby certain activators (for example, oxides of bismuth, manganese and lead) added to the oxides of host materials (for example, calcium, strontium and barium) cause a characteristic light emission (fluorescent spectra) when brought in close proximity to the flames of hydrogencontaining combustibles. The hydrogen atoms recombine, however, in the presence of diluent gases and at critical diluent concentrations the light emission is repressed. Moreover, at the point of the repression $(a)$ the flames of hydrocarbons ar $\epsilon$ rendered non-luminous, and $(b)$ in the presence of sodium salts the yellow $D$-line emission is also quenched. In further illustration of the part played by hydrogen atoms and their recombination by molecular collisions or on surfaces, it was shown how the heat conduction from a hydrogen flame to a surface was 20 per cent greater than that from a fairly dry carbon monoxide flame, although the calorific values are much the same.

The presence of oxygen atoms in carbon monoxide flames had been established some years ago in connexion with work on boiler availability, and there was little doubt that they were mainly responsible for the oxidation of sulphur dioxide to sulphur trioxide with the ultimate formation of sulphuric acid.

Another important problem concerned with the combustion of carbonaceous fuels was the presence of chemisorbed layers on the fuel surface. At low temperatures, an unstable carbon-oxygen-water-complex (peroxygen) 